\title{
COMPARISON BETWEEN FINITE ELEMENTS SIMULATION OF RESIDUAL STRESS AND COMPUTER VISION MEASUREMENTS IN A WELDING TIG PROCESS
}

\author{
Federico BIANCHI ${ }^{1,2}$, Luca PETRUCCI ${ }^{3}$, Lorenzo SCAPPATICCI ${ }^{1}$, Alberto GARINEI ${ }^{1,2}$, \\ Lorenzo BIONDI ${ }^{1,2}$, Marcello MARCONI ${ }^{1,2}$ \\ ${ }^{1}$ Guglielmo Marconi University - Department of Sustainability Engineering, Roma, Italy \\ ${ }^{2}$ Idea-Re S.r.l, via Pontani 39, 06128 Perugia, Italy \\ ${ }^{3}$ Engineering department, University of Perugia, 06125 Italy \\ e-mail: fbianchi@idea-re.eu, luca.petrucci1@studenti.unipg.it, 1.scappaticci@unimarconi.it, \\ a.garinei@unimarconi.it, 1.biondi@unimarconi.it, $\underline{\text { m.marconi@unimarconi.it }}$
}

\begin{abstract}
In this work, residual stresses arising after an industrial TIG welding process on an aerospace grade part are investigated. The customer demand for high product resistance and high dimensional accuracy calls for the control of the welding process and the minimisation of the residual stresses. Dimensional check of manufactured parts was traditionally performed in a quality room by means of coordinate measuring machines (CMM). For parts larger than 1 meter, this operation shows several issues, as the handling and the need for large and expensive measuring devices. These needs can be fulfilled by an innovative method that, through continuous dimensional check, allows to optimise the welding process parameters. This method is built on a post-process measurement of part shrinkage based on a Computer Vision technique, the outcome being a 3D reconstruction of the actual part. Moreover, the whole procedure is low-cost and time saving, as it can be performed with a conventional camera mounted on a tripod. A Finite Element Model (FEM) of the TIG process on the selected sample was developed. The result of the numerical model was compared with the Computer Vision-based post-process measurement. The simulation scenario predicted by Finite Element Analysis agrees with measurements.
\end{abstract}

\section{Welding Process, FEM simulation, Computer vision, Machine Learning}

\section{INTRODUCTION}

Welding is a fabrication process, widely used in the aeronautical, naval and metalworking fields, that merges two parts through a cord of molten material. The operating principle consist of an electric discharge produced by the electrical potential difference between an electrode and the sample. This discharge generates a heat beam penetrating the material and melting the two parts in contact. The pouring of inter gases create a protected atmosphere around the welded area to prevent oxidation. There are different welding methods: TIG, MIG/MAG, MMA, SAW and PLASMA are the most common. The Tungsten Inert Gas (TIG) welding process consists of the union of two parts by means of a tungsten electrode immersed in an atmosphere of Argon gas. In this process, the pieces instantly switch from room to very high temperature. This leads to a non-uniform temperature distribution, associated thermal strains and localised plastic deformation [1,2]. Indeed, one of the major issues after welding process, is the residual stress of the resulting piece and the reticular distortion due to local heating [3]. Inside the welded area, cracks and internal tensions are created and change the mechanical behaviour of the material, making it more subject to brittle fracture and allowing cold cracking. The reticular distortion often causes issues such as dimensional defects during assembly and increase in product costs due to the rework that the pieces must undergo. Several factors can contribute to the onset of stress and residual deformation. An important factor to consider is the plastic deformation in the base metal and the filler metal used in welding process. It depends solely on the structure of the material after manufacture $[4,5]$. The mechanical features of the material reflect the metallurgical conditions of the base and weld metal. Moreover, the process parameters include the welding method, heat input, preheating, welding sequence and retention conditions. In some steel welded parts, the transformation of solid-state austenite-martensite throughout cooling affects residual stress and distortion. Accurate predictions and the reduction of welding residual stress and deformation are very relevant in improving the quality of welded structures. FEM is a powerful numerical simulation tool and a good alternative to estimate welding residual stress [6,7]. FEM of the welding process is highly effective in predicting thermomechanical behaviour [8]. Other studies reported the comparison between F.E. simulations and X-ray measurements of residual stresses in spot welding [9]. Monitoring the actual deformation in a welding process is crucial to validate both the F.E.M. calculation and the process result. In the current 
manufacturing technological landscape, a crosssectoral monitoring technique is Computer Vision (CV). The industrial exploitation of this wide technique dates to several decades ago [10]. Nevertheless, its pervasive use is quite recent, thanks to more computing power and the availability of sophisticated optical devices. In welding processes, many efforts have been done in effective seam monitoring, together with Artificial Intelligence (AI) algorithms. In [11,12,13], images of the fusion bed and the seam were used to train Convolutional Neural Networks (CNN) to classify surface defects. In recent years, Digital Image Correlation (DIC) methods have been applied to monitor the shape of manufactured pieces. In [14], a simple experimental set-up allowed to estimate the deformation of a cylindrical specimen exposed to high pressure. Ali et al. [15], attempted to detect defect on small cylindrical pieces by means of a quite sophisticated mirror-based device. Xiao et al [16] monitored the dimensional accuracy of a small conical workpiece on a rotating platform with a fixed camera. In [17] a similar work was carried on, to check roundness of an automotive camshaft. The dimensional monitoring of large cylindrical pieces (diameter $>1 \mathrm{~m}$ ) during welding operations is more complex than smaller ones. Thus, a movable and versatile device is preferable to fixed and sophisticated ones. In this paper, we report a coordinated F.E.M. study on residual stresses and Computer Vision measurements to monitor part deformations. The goal is to obtain a reliable, cheap and easy-to-use device to perform dimensional check of large welded parts. This device should be managed by non-expert personnel.

\section{MATERIALS}

The sample under investigation is a quasiconical hollow part, composed of Nickel Alloy Haynes 230 [18], whose thermal and mechanical properties are reported in Table 1. The sample is composed of a nickel-chromium-tungstenmolybdenum alloy that shows high-temperature strength and excellent long-term thermal stability. Other relevant features include lower thermal expansion characteristics, as compared to most high-temperature alloys, and a pronounced resistance to grain coarsening with prolonged exposure to high temperatures.

The sample is part of a larger construction designated for the purpose of power production. The diameter of the sample is about 1.5 meters. In order to test the numerical simulation and to obtain data for Computer Vision analysis, a TIG weld has been performed on the part. This operation is needed to restore a heavily stressed area, as a result of an earlier shaping process. An image of the piece with the welded part is reported in Fig. 1.
Table 1. Haynes 230 Alloy physical properties

\begin{tabular}{|c|c|c|}
\hline \multirow{2}{*}{$\begin{array}{c}\text { Physical } \\
\text { property }\end{array}$} & $\begin{array}{c}\text { Temperature } \\
\left({ }^{\circ} \mathbf{C}\right)\end{array}$ & Value \\
\hline Density & RT & $8.97 \mathrm{~g} / \mathrm{cm}^{3}$ \\
\hline \multirow{2}{*}{$\begin{array}{c}\text { Thermal } \\
\text { diffusivity }\end{array}$} & RT & $24.2 \times 10^{-3} \mathrm{~cm}^{2} / \mathrm{s}$ \\
\cline { 2 - 3 } & 1000 & $48.2 \times 10^{-3} \mathrm{~cm}^{2} / \mathrm{s}$ \\
\hline $\begin{array}{c}\text { Thermal } \\
\text { conductivity }\end{array}$ & RT & $8.9 \mathrm{~W} / \mathrm{m}^{\circ} \mathrm{C}$ \\
\hline \multirow{2}{*}{ Specific heat } & 1000 & $28.4 \mathrm{~W} / \mathrm{m}^{\circ}{ }^{\circ} \mathrm{C}$ \\
\cline { 2 - 3 } & $\mathrm{RT}$ & $397 \mathrm{~J} / \mathrm{kg} \cdot{ }^{\circ} \mathrm{C}$ \\
\hline $\begin{array}{c}\text { Mean } \\
\text { coefficient of } \\
\text { thermal } \\
\text { expansion }\end{array}$ & 1000 & $617 \mathrm{~J} / \mathrm{kg} \cdot{ }^{\circ} \mathrm{C}$ \\
\cline { 2 - 3 } & $\mathrm{RT}$ & $11.8 \times 10^{-6} \mathrm{~m} / \mathrm{m} \cdot{ }^{\circ} \mathrm{C}$ \\
\hline $\begin{array}{c}\text { Dynamic } \\
\text { modulus of } \\
\text { elasticity }\end{array}$ & 1000 & $16.1 \times 10^{-6} \mathrm{~m} / \mathrm{m} \cdot{ }^{\circ} \mathrm{C}$ \\
\cline { 2 - 3 } & 1000 & $209 \mathrm{GPa}$ \\
\hline
\end{tabular}

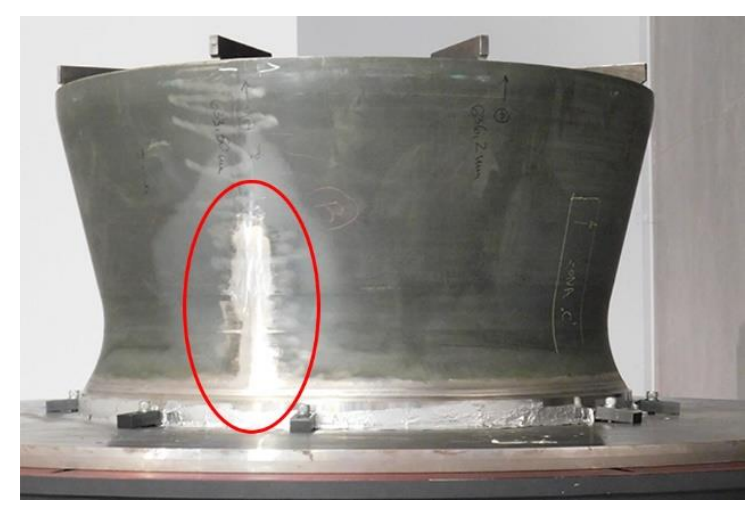

Fig. 1. The piece under investigation. The red circle evidences the TIG welding.

\section{NUMERICAL SIMULATION}

\subsection{Methods}

When dealing with large parts ( $>1$ meter), the challenge of the numerical modeling is to keep the model light and robust, while maintaining the physic significance of the process. The actual welding process is quite complex: the welding tool is motionless and the conical structure is constrained to a rotating platform; the control of the rotational speed of the platform actually drives the velocity of the weld bead growth along the circumferential direction. In order to achieve a versatile - but at the same time - representative model of such a process, some simplifications were considered. In this section we describe the numerical investigation methodologies that have been used.

\subsection{The numerical model}

In order to obtain an estimate of the residual deformation that occurs during the welding process, a one-way Thermal Transient - Structural Transient Finite Element Analysis (FEA) was implemented. The model itself is capable of consider the effect of the local heating due to the rotating welding process on the deformation of the structure. 
Essentially, the deformation due to welding process was simulated considering, in a numerical environment, two distinct and interconnected phases. In the first phase, a transient analysis of the thermal effect induced by the local action of the welding tool was set on. In the second phase, a transient structural case was resolved according to the transient thermal loads acting. Since the structure is axial-symmetric in terms of geometry and constraints but not in terms of thermal loads, it was necessary to define a discrete model of the entire conical structure. To maintain the mesh dimension reasonable, the conical structure was discretised by means of shell elements. The thickness of the solid was modelled assigning the thickness of one shell element and this was not a big deal since the ratio between thickness of the sheet metal and the other dimensions is much less than 1. Then, the solid was modelled motionless, with the moveable welding tool along the circumferential direction. In this way it was possible to obtain a model with fixed mesh, with benefits for versatility. The welding tool itself was modelled as a fixed heat flux, acting, for incremental instants, on adjacent elements of the mesh. By suitably defining a fixed pre-set circumferential dimension for the shell elements, it was possible to simulate the progression of the welding tool with minimal computational cost, at the expense of the size of the whole structure.

Such a discrete model is composed of 377400 elements (QUAD4 thin shell) and 375920 nodes, and each shell element is $6,35 \mathrm{~mm}$ thick.

The part was modelled using Nickel Alloy Haynes 230, whose thermal and mechanical properties are reported in Table 1.

\subsection{The Transient Thermal Analysis (TTA)}

The simulated welding process advances at the speed of $15 \mathrm{~cm}$ per minute. After covering an angular distance of about $45^{\circ}$ the process is put on stand-by to carry out dimensional checks.

The TTA was built to run for 150 seconds. In the first 90 seconds, for each second of simulation a trapezoidal profile Heat flux $\left(200 \mathrm{~W} / \mathrm{mm}^{2}\right)$ was subsequently applied for one second on the middle elements of the weld bead. In this way, since the circumferential dimension of the shell element was set at $2,5 \mathrm{~mm}$, the thermal analysis in 90 seconds covered about $45^{\circ}$ as an angular distance. The remaining 50 seconds were left to settle the conductive heat transfer in the structure. The solver was programmed to run 4 steps of simulation per each second of analysis.



Fig. 2. Sketch of the single point experimental measure by thermocouple, on the point indicated by (A).

\subsection{Boundary conditions}

The starting temperature of TTA is set at $22^{\circ} \mathrm{C}$. The faces of the conical surface were considered convective with a coefficient of $1 \mathrm{e}-5 \mathrm{~W} / \mathrm{mm}^{2 \circ} \mathrm{C}$, that is the convective coefficient of a natural convection.

\subsection{Results of TTA}

The thermal profile implemented in the numerical analysis was obtained according to the nominal heat outflowing from the welding head. Fig. 3 describes the thermal features of the heated zone. The temperature pattern was validated by a single point thermocouple experimental measure, in the area indicated with " $A$ " in Fig. 2. The detected temperature in " $\mathrm{A}$ " was $\mathrm{T}(\mathrm{A})=(360 \pm 20){ }^{\circ} \mathrm{C}$ after a time $t_{\mathrm{s}}=(32 \pm 4) \mathrm{s}$ upon the passage of the welding head.

Fig. 4 represents the temperature distribution at the end of the simulation. Welding direction goes from left to right.



Fig. 3. Temperature pattern obtained by simulation into the heated zone.

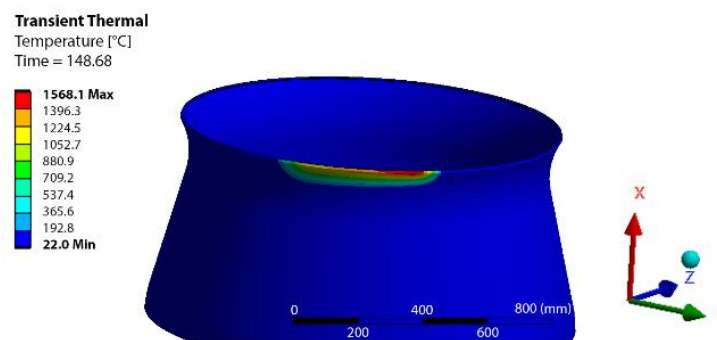

Fig. 4. Results for the TTA on the simulated welding process. 


\subsection{The Transient Structural Analysis (TSA)}

In the one-way coupled thermal structural analysis, the thermal field solution (body temperature) is taken as input for the structural dynamic analysis. This has been defined in the nonlinear field including large deformations. We performed a 10 second analysis. An integration time step of 1/20 seconds was defined to catch solution convergence. The conical structure was considered fixed at ground by its larger circumferential base.

\subsection{Results of TSA}

Fig. 5 represents the Equivalent Von Mises Stress after 10 seconds of simulation.


Fig. 5. Equivalent Von Mises Stress after 10 seconds of simulation.

This state of structural stress likely induces residual deformations. For this reason, the directional deformation along of the axis of the cone was evaluated. Three sections (Fig. 6) were identified in the area subject to heating due to welding (approximately a "slice" with an angular opening of about $45^{\circ}$ ):

- Section 1 - corresponding to $0^{\circ}$ (starting point of the welding).

- Section 2- corresponding to 30 (intermediate point of welding)

- Section 3 - corresponding to $45^{\circ}$ (end point of the welding).


Fig. 6. Description of the identified sections chosen for the deformation analysis.

Deformations along the cone axis are plotted in the following graph (Fig. 7). It is useful to remember that, dealing with dynamic simulation, the deformations detected vary over time, depending on the variation of the thermal field.

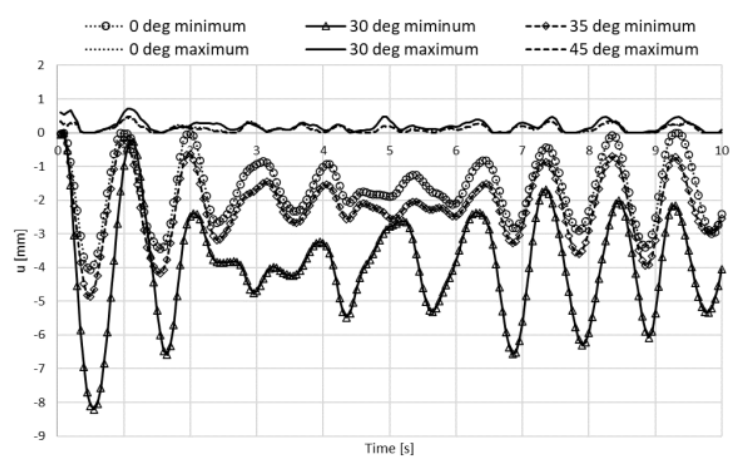

Fig. 7. Deformations along the cone axis (X axis for the simulation) for three

characteristic sections: 0,30 and 45 degrees, versus simulation time.

Performing an integral over the simulation volume, it is possible to find the absolute maximum and minimum deformation, regardless of the axis of reference. The result of such calculation is depicted in Fig. 8.

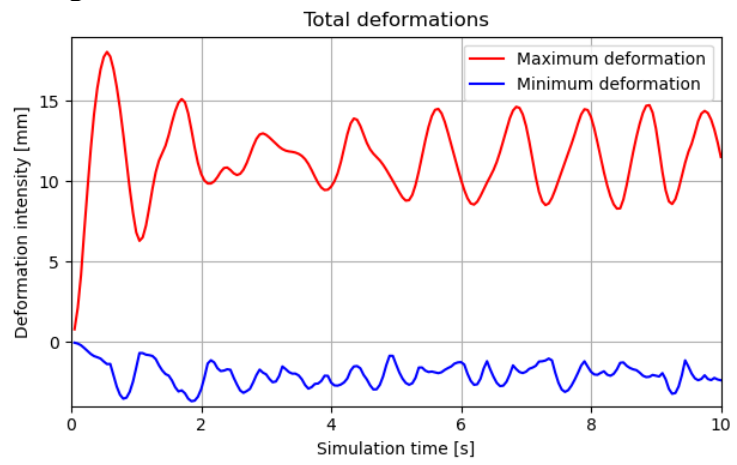

Fig. 8. Intensity of total deformation in over the piece versus simulation time.

Fig. 9 shows the deformation along the upper circumferential profile, compared to the undeformed configuration, that is zero deformation.
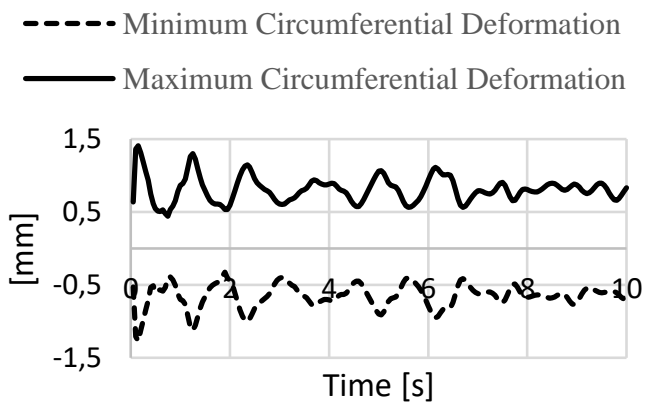

Fig. 9. Intensity of maxima and minima deformations along the upper circumferential profile, versus simulation time.

\section{COMPUTER VISION ANALYSIS}

\subsection{Edge detection method}

Among the large amount of computer vision analysis methods, in this work we pick the simple use of a commercial camera. Taking advantage of the symmetry of the piece under investigation, we 
use a rotating platform to take photos of the entire surface. This kind of inspection is very powerful when it is necessary to point out deviations from roundness and to digitise the whole outer surface of the piece. Nevertheless, this method is cheap, fast, and the instrumentation (the camera plus the tripod) can be delivered where necessary, if it is needed to monitor many manufacturing processes on the same part. Clearly, this method is only available when dealing with cylindrical or conical pieces $[16,17]$

The experimental set-up consists of a rotating platform, as in Fig. 10 - on which the quasi-conical structure to be measured is installed - and a camera fixed on a tripod to take pictures of the sample. The motor driven platform can rotate on its axis at constant speed. Meanwhile, the digital camera acquires images during a complete revolution of the piece, so that 180 frames were obtained at equal time and degrees steps (one each two degrees). A sequence of operations was performed to extract the part profile from each frame.

Each image has been pre-processed to let the edge detection algorithm work easily. The whole sequence is explained in Fig. 11. In the first place, each image has been cropped to remove most of the background and the vertical borders, to maintain the relevant edges on a plane, parallel to that of the camera. Then, the image has been further cropped, as only the upper edge has been processed. In order to gain absolute scale in millimetres, measurements of the height of the part have been performed at fixed rotating positions with a digital gauge. The height values have been compared to the proper images to obtain the resolution in $\mathrm{mm} / \mathrm{pixel}$. The final resolution resulted to be $R=1.6 \mathrm{~mm} / \mathrm{pixel}$, on the plane where the profile per each image lies.

Finally, the Canny algorithm was implemented. An asymmetric gaussian blur was applied prior to the actual edge detection, to consider the horizontality of the borders and to discard vertical possible unwanted features, like light reflections and written notes on the part surface. The Canny parameters were adjusted on few test images, then batch processing was implemented to speed-up the procedure. The edge detection algorithm result is depicted in the bottom-right part of Fig. 12.

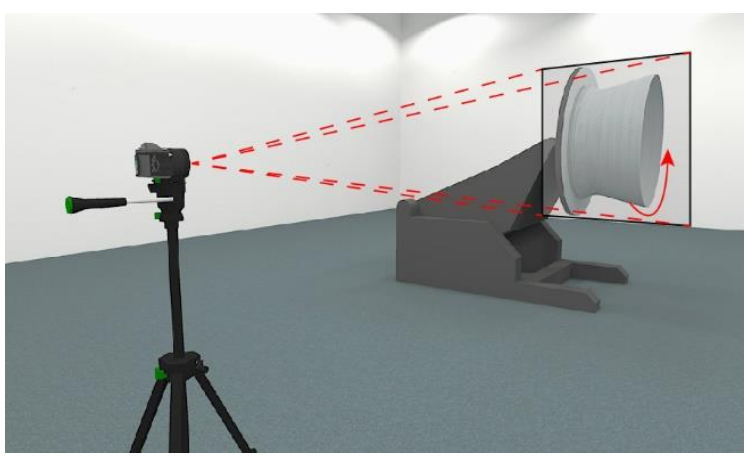

Fig. 10. Experimental set-up for image capture

\subsection{Point cloud reconstruction}

The 180 black\&white matrices obtained from edge detection need to be properly treated to get a $3 \mathrm{D}$ point cloud. Firstly, the edge pixels were converted into three-dimensional points, assigning them $\mathrm{X}, \mathrm{Y}$ and $\mathrm{Z}$ coordinates. The $\mathrm{Z}$ axis has been chosen to be the height of the piece, i.e. the direction along the axis of symmetry; the other direction being the $\mathrm{X}$ axis. In this way all profiles lie on the $\mathrm{XZ}$ plane.

It is necessary to apply a translation of the profile set along the $\mathrm{X}$ axis to reach the correct distance of the borders from the centre of symmetry. The parameters of the translation are obtained by looking back at the cropping procedures explained in the previous section. Once the data set is translated, it has to be rotated around the $\mathrm{Z}$ axis. Each profile has been rotated progressively by $2^{\circ}$ from the previous one. The result is reported in Fig. 13.



Fig. 11. Flowchart of point cloud reconstruction. 


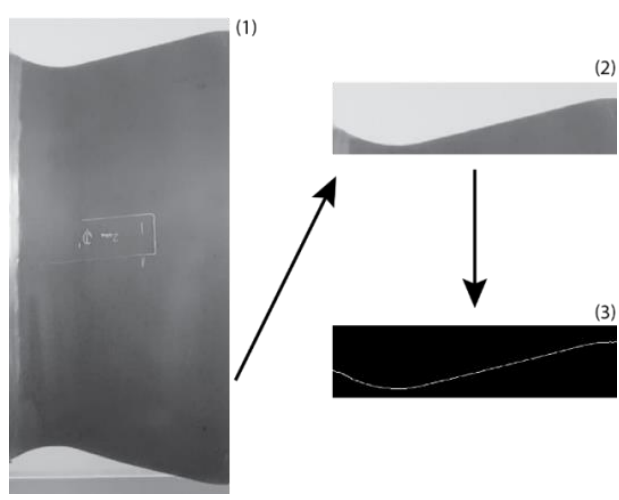

Fig. 12. Image pre-processing and edge detection

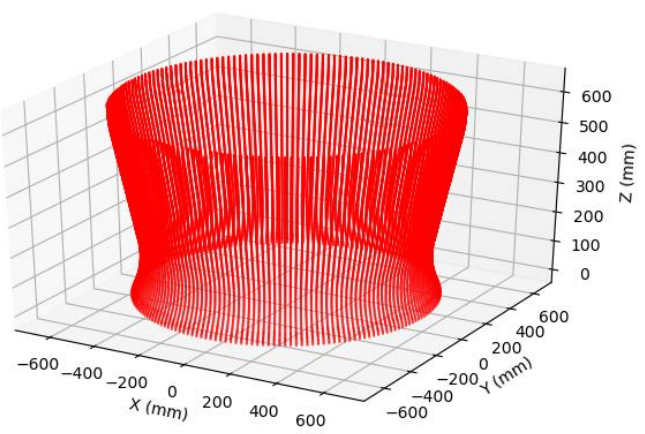

Fig. 13. Rebuild point cloud from the detected edges, after spatial placement.

\subsection{Point cloud vs. Model mesh}

The point cloud and the CAD model of the part were compared using the free software CloudCompare v2.11. The distance between the point cloud and the mesh (obtained from the CAD model) is considered as the distance between each point from the nearest mesh geometrical centre. Notably, the mesh was manipulated to maintain only the external shell of the part, to consistently perform the comparison. Prior to compute the distance, alignment between the two objects was achieved, overlapping the point resulting from the intersection of the $\mathrm{Z}$ axis and the base plane, for the two objects. The result of the computation is reported in Fig. 14. The colour indicates the distance of each point from the mesh, calculated normally form the surface of the structure. Red colour means that the cloud (i.e. the real object) lies outside the mesh, blue colour means that the point cloud lies inside the mesh.

To better understand the deviation of the welded piece from the theoretical one, the difference values have been reported in a graph for three significant levels: on the upper circumferential profile, at a height of $360 \mathrm{~mm}$, and at a height of $100 \mathrm{~mm}$ from the base. The graphs are reported in Fig. 15.

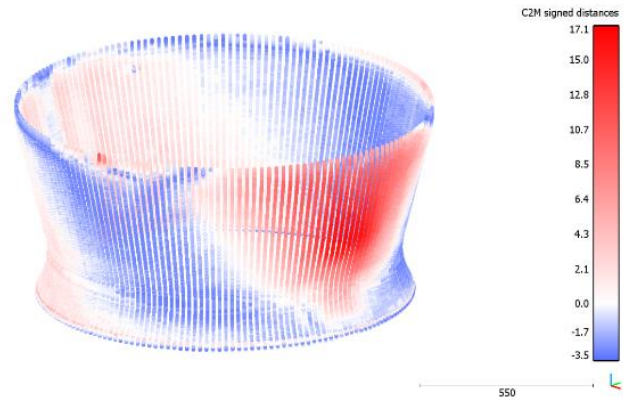

Fig. 14. Point cloud of the manufactured piece colored with the differences between the designed part and the actual one. Red points represent the actual part lying outside the theoretical mesh, blue points represent actual part lying inside.
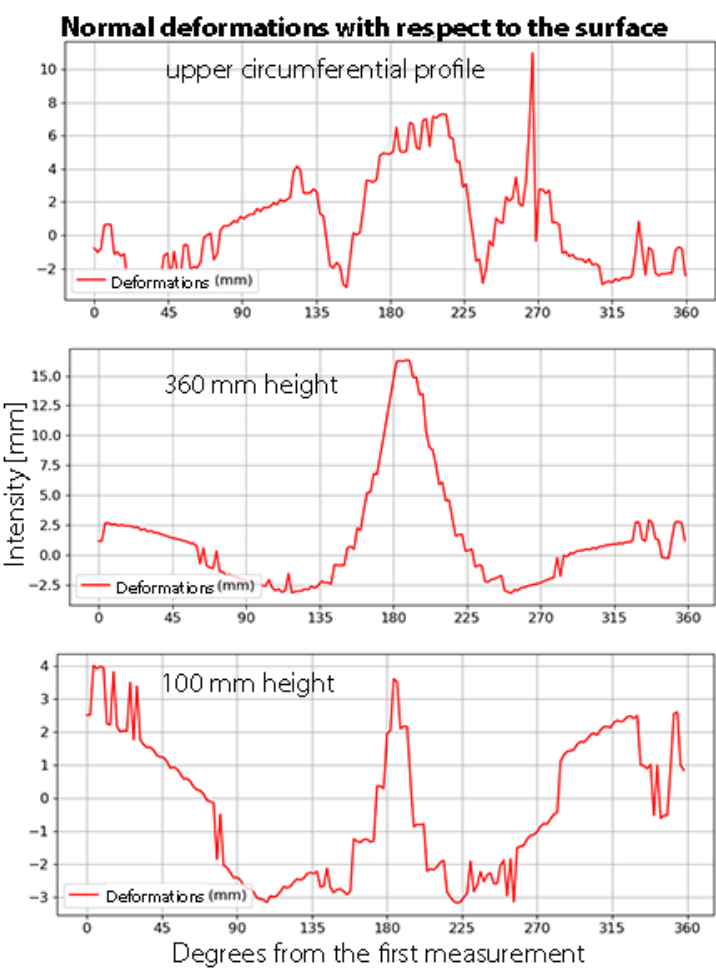

Fig. 15. Graph of normal deformations taken at three significant altitudes from the piece base: upper crown, medium height and near the base.

\section{DISCUSSION}

The results obtained from the numerical simulation show that conical structure, when subject to a physical process of high heating, undergoes deformations which manifested as residuals after loading. The deformations themselves are rather marked both along and normally to the axis of symmetry. Analysis of total residual deformations led to a result of a maximum ranging between 15 and $8 \mathrm{~mm}$ and a minimum of $2.5 \mathrm{~mm}$, after a simulation of 10 second. Computer Vision (CV) measurements reported a maximum displacement, with respect to the theoretical model, of $16 \mathrm{~mm}$, and a minimum of $3 \mathrm{~mm}$. The CV 
experiment can be considered as performed at $t=$ $\infty$, with respect to the simulations. Taking into account the experimental error of about $1.6 \mathrm{~mm}$ for the CV measurements, it is reasonable to claim that the numerical simulation and the $\mathrm{CV}$ analysis are in good agreement, thus it is possible to forecast the structural and dimensional modification of the tested structure by means of a simulation after a TIG welding process.

\section{CONCLUSION}

This work aims at developing a fast, easy-to-use and cheap method to perform dimensional check of large manufactured parts. The FEA of welding process allows to grasp the thermal characteristics of the phenomenon and its impact on the structural features of the component under analysis. This method has been validated by the $\mathrm{CV}$ measurements. A careful setting up of the CV validation process allows to obtain feedback that could be used to redefine some characteristics of simulated physics, to reach more accurate results. The CV measurements, individually possess high diagnostic power in a production process also without FEA, thus can be exploited alone. Such preliminary calculation is very time and money saving when dealing with expensive materials and numerous production processes. Besides, postprocess imaging can clarify if the part being examined lies into the requested tolerances.

\section{FUTURE WORK}

The analysis carried out in this work highlighted the complexity of welding a large element due to the shrinkage of the material. The latter, in fact, compromises the final shape of the piece preventing to reach the shape tolerance expected by the customer. Minimisation of shape defects calls for optimisation of the welding process. Many effort is done on this topic. A recent work exploits the use of Genetic Algorithms to optimise the welding sequence [19]. In this work the coordinated use of FEA and robotic is explored and presented as low time-consuming. Other data-driven approaches describe the use of data (produced by pervasive process monitoring) to generate optimised production process models [20]. We plan to collect data on a wide range of quantities representing the process parameters such as arc current, voltage and temperature, surface temperature, wire and torch feeding speed and other significant features. These data will be recorded in real time, during the production process. The resulting time series (together with the CV data already available) will be employed to build data-driven schemes of the process, by means of proper optimisation algorithms. The data will also be used to train Recurrent Neural Networks (RNN), in order to perform real-time Anomaly Detection on the welding process. Several studies reported that, by feeding the algorithms with control parameters of the welding machine, it is possible to obtain a prediction of the welding seam [21,22] or of the breaking load [23]. By monitoring these parameters in real-time, a smoother weld could be achieved and shape defects reduced.

The ultimate goal is a scenario where the algorithms will be able to interact with the process, regulating the optimal parameters while the process is going on. The algorithms will manage both data from process parameters (upstream of manufacturing operation) and from $\mathrm{CV}$ measurements (downstream of operation), in a feedback system. It will be possible to have a controlled and optimised system with low cost technologies able to satisfy the customer's specifications.

\section{SOURCE OF FUNDING}

This paper is the result of the project implementation: "NCM-PRO: Innovative integrated control in Numerical Control Manufacturing PROcesses", funded by the POR-FESR 2014-2020 - Regional Operative Programme - European Fund for Regional Development of Umbria Region (Italy).

\section{ACKNOWLEDGMENTS}

The authors want to thank NCM Spa enterprise (Via A. Vici, 34 - Z.I. La Paciana, 06034 Foligno PG, Italy) for the support given in terms of professional knowledge and for having made available its areas and instrumentation.

\section{REFERENCES}

1. Chang PH, Teng TL. Numerical and experimental investigations on the residual stresses of the buttwelded joints. Computational Materials Science. 2004;29(4):511-522. https://doi.org/10.1016/j.commatsci.2003.12.005;

2. Haelsig A, Kusch M, Mayr P. New findings on the efficiency of gas shielded ARC welding. 2009.

3. Deng D. FEM prediction of welding residual stress and distortion in carbon steel considering phase transformation effects. Materials and Design. 2009;30(2):359-366. https://doi.org/10.1016/j.matdes.2008.04.052.

4. Mackerle J, Pietraszkiewicz W, Konopiska V. Modelling and simulation in materials science and engineering related content finite element analysis and simulation of welding: a bibliography (1976 1996) Finite element analysis and simulation of welding.

5. Jain R, Pal SK, Singh SB. Finite element simulation of pin shape influence on material flow, forces in friction stir welding. International Journal of Advanced Manufacturing Technology. 2018;94(58):781-1797. https://doi.org/10.1007/s00170-0170215-3.

6. Ogawa K, Deng D, Kiyoshima S, Yanagida N, Saito $\mathrm{K}$. Investigations on welding residual stresses in 
penetration nozzles by means of 3D thermal elastic plastic FEM and experiment. Computational Materials Science. 2009 45(4):1031-1042. https://doi.org/10.1016/j.commatsci.2009.01.008.

7. Hwang JD, Lin HJ, Hwang JD, Hu CT. Numerical Simulation of Metal Flow and Heat Transfer during Twin Roll Strip Casting. ISIJ International. 1995; 35(2):170-177. https://doi.org/10.2355/isijinternational.35.170.

8. Dean D, Hidekazu M. Prediction of welding residual stress in multi-pass butt-welded modified $9 \mathrm{Cr}-1 \mathrm{Mo}$ steel pipe considering phase transformation effects. Computational Materials Science. 2006;37: 209-219. https://doi.org/10.1016/j.commatsci.2005.06.010.

9. Nodeh IR, Serajzadeh S, Kokabi AH. Simulation of welding residual stresses in resistance spot welding, FE modeling and X-ray verification. Journal of Materials Processing Technology. 2007;5:60-69. https://doi.org/10.1016/j.jmatprotec.2007.11.104.

10. Agin GJ. Computer Vision Systems for Industrial Inspection and Assembly. Computer. 1980;13(5):1120. https://doi.org/10.1109/MC.1980.1653613.

11. Bacioiu D, Melton G, Papaelias M, Shaw R. Automated defect classification of SS304 TIG welding process using visible spectrum camera and machine learning. NDT \& E International. 2019;107 https://doi.org/10.1016/j.ndteint.2019.102139.

12. Zhu H, Ge W, Liu Z. Deep Learning-based classification of weld surface defects. Applied Sciences. 2019;9(16):3312. https://doi.org/10.3390/app9163312;

13. Sizyakin R, Voronin V, Gapon N, Zelensky A. Pižurica A. Automatic detection of welding defects using the convolutional neural network. Proc. SPIE 11061, Automated Visual Inspection and Machine Vision III, 2019;110610E.

14. Sang Y, Zhao J, Duan F. Ji X. In-plane deformation monitoring of a cylindriscal specimen using a simple approximate method combined with two-dimensional digital image correlation. Rev. Sci. Instrum. 2019;90: 1115107. https://doi.org/10.1063/1.5100857;

15. Ali M, Mailah M, Kazi S. Tang H. Defects detection of cylindrical object's surface using vision system. Recent Researches in Computational Intelligence and Information Security, 2011:222-227.

16. Xiao G, Li Y, Xia Q, Cheng, Chen W. Research on the on-line dimensional accuracy measurement method of conical spun workpieces based on machine vision technology. Measurement. 2019:148. https://doi.org/10.1016/j.measurement.2019.106881.

17. Ayub MA, Mohamed AB. Esa AH. In-line inspection of roundness using machine vision. Procedia Technology. 2014;105:807-816. https://doi.org/10.1016/j.protcy.2014.09.054.

18. Haynes International. 2020. https://www.haynesintl.com/alloys/alloyportfolio_/High-temperature-Alloys/HAYNES-230ALLOY/principal-features.aspx. Website visited 1119-2020

19. Romero J, Saha B, Toledo G. Beltran-Bqz D. Welding Sequence Optimization Using Artificial Intelligence Techniques, an Overview. SSRG International Journal of Computer Science and Engineering (SSRG-IJCSE). 2016;3:91-95. https://doi.org/10.14445/23488387/IJCSE-V3I11P115.

20. Yin S, Ding SX, Xie X, Lu H. A Review on Basic Data-Driven Approaches for Industrial Process Monitoring. IEEE Transactions on Industrial
Electronics. 2014:61(11):6418-6428.

https://doi.org/10.1016/10.1109/TIE.2014.2301773.

21. Dutta P, Pratihar DK. Modeling of TIG welding process using conventional regression analysis and neural network-based approaches. Journal of Materials Processing Technology. 2007;184(1-3): 56-68.

https://doi.org/10.1016/j.jmatprotec.2006.11.004.

22. Gao X, You D, Katayama S. Seam tracking monitoring based on adaptive Kalman filter embedded elman neural network during high-power fiber laser welding. IEEE Transactions on Industrial Electronics. 2012;59(11):4315-4325. https://doi.org/10.1109/TIE.2012.2193854.

23. Pal S, Pal SK, Samantaray AK. Artificial neural network modeling of weld joint strength prediction of a pulsed metal inert gas welding process using arc signals. Journal of Materials Processing Technology. 2008;202(1-3):464-474.

https://doi.org/10.1016/j.jmatprotec.2007.09.039.

Received 2020-11-19

Accepted 2021-04-12

Available online 2021-04-13

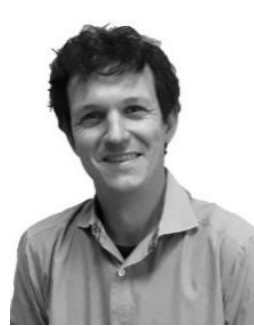

Federico BIANCHI graduated in Physics at University Perugia, Italy, where he also obtained his $\mathrm{PhD}$ in Biophysics.

Experimental by vocation, he always combined this aspect with his ability in data analysis.

$\mathrm{He}$ is currently research fellow at Guglielmo Marconi University, with a grant by Idea-Re Srl, where he focuses on innovative topics such as smart additive manufacturing, Computer Vision and Machine Learning.

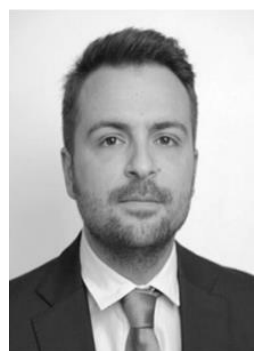

Luca PETRUCCI is a $\mathrm{PhD}$ student at the Department pf Engineering of Perugia University. His research activity focuses mainly on the application of machine learning techniques to internal combustion engines and industrial processes. The algorithms are used as virtual sensors, fault detection, process optimization, image analysis and end-line quality control.

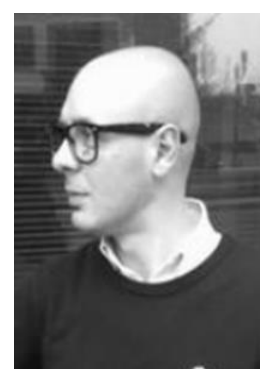

\section{Lorenzo SCAPPATICCI}

is a research fellow at Guglielmo Marconi University, Rome. His research interests deal mainly with Finite Element Methods for structural optimization of vehicles and for bioengineering applications; with the analysis of fluid-structures interactions; with vibration analysis and wind tunnel testing of vehicles. 


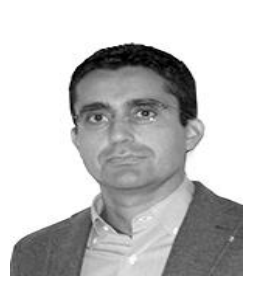

Alberto GARINEI graduated in Mechanical Engineering at University of Perugia, Italy. He has over 15 years of experience in applied research projects and is Full Professor in Mechanical and Thermal Measurements at Guglielmo Marconi University of Rome, Italy. His main research activities comprise: measurements techniques, sensors and devices for mechanical and thermal measurements, wind energy, materials characterization, research metrics and metrology. $\mathrm{He}$ is in the Italian Ministry of Economic Development registers of Qualified Managers for Technological Innovation and of Technological Innovation Experts. $\mathrm{He}$ is cofounder and Chief Scientific Officer at Idea-Re Srl.



Lorenzo BIONDI graduated in Mechanical Engineering at University of Perugia, Italy, where he also obtained his PhD in Energy Engineering. He has over 15 years of experience in applied research projects and is currently Adjunct Professor in Manufacturing Technology and Systems at Guglielmo Marconi University of Rome, Italy.

His main research activities comprise: renewable energy, biofuels, energy systems, energy efficiency, low-energy buildings. He is in the Italian Ministry of Economic Development registers of Qualified Managers for Technological Innovation and of Technological Innovation Experts. $\mathrm{He}$ is co-founder and Head of Industry 4.0 at Idea-Re Srl.

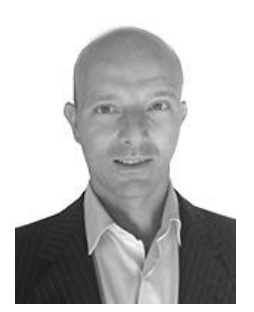

Marcello MARCONI graduated in Mechanical Engineering at University of Perugia, Italy, where he also obtained his $\mathrm{PhD}$ in Industrial Engineering. He has over 15 years of experience in applied research projects and is currently Adjunct Professor in Industrial Mechanical Plants at Guglielmo Marconi University of Rome, Italy.

His main research activities comprise: energy systems, refuse and wastewater management, water technology, Industry $4.0 . \mathrm{He}$ is in the Italian Ministry of Economic Development registers of Qualified Managers for Technological Innovation and of Technological Innovation Experts. $\mathrm{He}$ is cofounder, President and CEO at IdeaRe Srl.
Idea-Re Srl is an innovative startup with a high-intensity knowledge application created with the specific intent of providing integrated services to companies in the field of Research and Development and, in a broader sense, of providing strategic consulting services linked to innovation, based on an original multidisciplinary approach to $R \& D$ activities. Idea-Re is the link between the world of production and that of knowledge, as it interprets innovation according to a paradigm combining the needs of companies with the scientific approach of the research. 